\title{
The role of self-esteem in Internet addiction within the context of comorbid mental disorders: Findings from a general population-based sample
}

\author{
KATRIN SEVELKO ${ }^{1}$, GALLUS BISCHOF ${ }^{1}$, ANJA BISCHOF $^{1}$, BETTINA BESSER $^{1}$, ULRICH JOHN ${ }^{2}$, \\ CHRISTIAN MEYER ${ }^{2}$ and HANS-JÜRGEN RUMPF ${ }^{1}$ \\ ${ }^{1}$ Department of Psychiatry and Psychotherapy, University of Lübeck, Lübeck, Germany \\ ${ }^{2}$ Institute of Social Medicine and Prevention, University Medicine Greifswald, Greifswald, Germany
}

(Received: May 24, 2018; revised manuscript received: November 20, 2018; accepted: November 22, 2018)

\begin{abstract}
Background and aims: Internet Addiction (IA) has consistently been related to comorbid psychiatric disorders and lowered self-esteem. However, most studies relied on self-report questionnaires using non-representative samples. This study aims to analyze the relative impact of self-esteem and comorbid psychopathology with lifetime IA in a population-based sample of excessive Internet users using clinical diagnoses assessed in a personal interview. Methods: The sample of this study is based on a general population survey. Using the Compulsive Internet Use Scale, all participants with elevated Internet use scores were selected and invited to a follow-up interview. Current DSM-5 criteria for Internet gaming disorder were rephrased to apply to all Internet activities. Out of 196 participants, 82 fulfilled the criteria for IA. Self-esteem was measured with the Rosenberg's Self-Esteem Scale. Results: Self-esteem is significantly associated with IA. For every unit increase in self-esteem, the chance of having IA decreased by $11 \%$. By comparison, comorbidities such as substance-use disorder (excluding tobacco), mood disorder, and eating disorder were significantly more likely among Internet-addicted than in the non-addicted group. This could not be reported for anxiety disorders. A logistic regression showed that by adding self-esteem and psychopathology into the same model, self-esteem maintains its strong influence on IA. Discussion and conclusions: Self-esteem was associated with IA, even after adjustment for substance-use disorders, mood disorder, and eating disorder. Self-esteem and psychopathology should be considered in prevention, intervention measures, as well as in the conception of etiological models.
\end{abstract}

Keywords: Internet addiction, self-esteem, comorbidity, psychopathology, prevalence

\section{INTRODUCTION}

Rising concerns regarding frequent and excessive use of certain Internet activities, such as online video games or social media, have opened up a debate over a potential new mental disorder called Internet addiction (IA). Although the Internet may offer many opportunities and benefits, the use of some online activities can become dysfunctional, when they take up an excessive amount of time and energy, while other aspects of life are neglected (Andreassen \& Pallesen, 2014). These pathological behavioral patterns are often detected in teenagers and adolescents (Rumpf et al., 2014). Although other researchers have worked on similar constructs, like Griffiths (1995) who worked on technological addiction and Shotton (1991) on computer addiction, Young $(1996,1999)$ has been the first to publish a study on the specific topic of addictive Internet use or IA. Since then, two decades of research into this new area shed some light on mechanisms of IA. This led to the inclusion of Internet gaming disorder (IGD) into the fifth edition of Diagnostic and Statistical Manual of Mental Disorders (DSM-5), though under Section 3 as a condition that requires further study before becoming an official mental disorder (American Psychiatric Association, 2013) and the
World Health Organization (WHO) included Gaming Disorder into the new release version of the International Classification of Diseases 11th Edition (ICD-11; WHO, 2018).

Prior to the inclusion of IGD in the DSM-5, differences in assessment instruments have made it difficult to compare the findings to build a uniform and standardized framework around IA. In a review, Kuss, Griffiths, Karila, and Billieux (2014) summed up 68 epidemiological studies about IA and found that among them 21 different diagnostic tools were used to determine IA. The authors argue that varying measures and cut-offs make comparisons between data hard and cause varying prevalence estimates. In addition, most screenings are not thoroughly validated to distinguish between clinically relevant users and regular users. Another problematic aspect of IA research is the data collection. Data are mostly gathered with online questionnaires, which are an easy way to gather huge amounts of data but lacks satisfying clinical assessment (Kardefelt-Winther et al., 2017;

* Corresponding author: Katrin Sevelko; Department of Psychiatry and Psychotherapy, University of Lübeck, Ratzeburger Allee 160, 23538 Lübeck, Germany; Phone: +49 1767069 5363; Fax: +49 451500 3480; E-mail: katrin.sev@web.de

This is an open-access article distributed under the terms of the Creative Commons Attribution-NonCommercial 4.0 International License, which permits unrestricted use, distribution, and reproduction in any medium for non-commercial purposes, provided the original author and source are credited, a link to the CC License is provided, and changes - if any - are indicated. 
Lampen-Imkamp \& te Wildt, 2009). However, with the inclusion of IGD and the establishment of criteria in the DSM-5, the first step toward a standardized data collection is made and has stimulated research in this area.

Many of the earlier studies have concentrated on IGD. Notwithstanding, there is increasing evidence about the clinical relevance of social networking site (SNS) addiction. SNS addiction is under consideration to be an independent condition by some researchers (Griffiths, Kuss, \& Demetrovics, 2014; Müller, Beutel, Egloff, \& Wölfling, 2014; Rumpf et al., 2014).

In IGD as well as SNS addictions, self-esteem has been identified as a risk factor and predictor in developing and maintaining a problematic behavior toward Internet activities (Andreassen et al., 2016; Beard, Haas, Wickham, \& Stavropoulos, 2017; Brand, Young, Laier, Wölfling, \& Potenza, 2016). Generally speaking, low self-esteem causes stress and negative feelings, which can be distracted or compensated by engaging in gaming or social networking (Kim \& Haridakis, 2009). Kardefelt-Winther (2014) proposes that the desire to play online video games and the problematic engagement toward it comes from the need to compensate for psychosocial problems. In SNS addiction, self-esteem also plays an important role. Positive feedback from SNS increased self-esteem and well-being, whereas negative feedback decreased both (Valkenburg, Peter, \& Schouten, 2006). A large scale study linked addictive social media use to higher narcissism and lower self-esteem, suggesting that SNSs are used for coping with low selfesteem and for an ego boost, which makes those websites addictive for vulnerable people (Andreassen, Pallesen, \& Griffiths, 2017).

Besides self-esteem, psychopathological conditions and symptoms seem to contribute to IA as well (Kuss et al., 2017). Research conducted over the past years found that IA is linked to substance abuse, depression, social phobia and phobic anxiety, and antisocial/aggressive behavior (Beutel et al., 2011; Ko et al., 2006; Kuss et al., 2014). In addition, a meta-analysis conducted by Ho et al. (2014) has found that alcohol abuse, attention-deficit disorder, hyperactivity, depression, and anxiety are significantly associated with IA.

One limitation of the research, to date, is whether low self-esteem may be explained as a consequence of psychiatric disorder that is comorbid to IA or whether it may hold as a predictor even after adjustment for psychiatric disorder. For instance, a study by Schmitz, Kugler, and Rollnik (2003) showed that psychiatric patients suffer from lower rates of self-esteem in general. This was especially the case in patients with comorbid disorders. A second limitation is that past studies have used short questionnaires instead of comprehensive diagnostic interviews based on DSM-5 criteria. As a third limitation, it has to be mentioned that most studies have not been based on general population samples.

The aim of this study was to investigate associations of self-esteem with IA under consideration of comorbid psychiatric disorders. The following hypotheses are tested: (a) Participants with low self-esteem are more likely to have IA; (b) depression, substance-use disorder, and anxiety disorder frequently occur in individuals with IA compared to those without; and (c) self-esteem is associated with IA, independently from psychiatric comorbidity.

\section{METHODS}

\section{Participants}

Participants were recruited from the sample of the Pathological Gambling and Epidemiology (PAGE) study. For this study, the Institute of market and social research infas recruited 15,023 participants, through randomly computergenerated mobile $(n=1,001)$ or landline numbers $(14,022)$. In a telephone interview, participants aged 14-64 years were enquired about gambling behavior and Internet use (Meyer et al., 2015). A total of 8,132 participants reported private Internet use for at least $1 \mathrm{hr}$ on a typical day of the week or on the weekend. These participants were additionally asked about Internet-related problems using the Compulsive Internet Use Scale (CIUS; Meerkerk, Van Den Eijnden, Vermulst, \& Garretsen, 2009). For this study, a very low and sensitive cut-off score of 21 or more points was chosen to include all participants with potential IA. Accordingly, 685 individuals met these criteria. Of them, 307 agreed to be contacted for further studies. Figure 1 further illustrates the reasons for non-participation, leaving 196 participants for a follow-up interview.

After the interview, the participants could be divided into two subgroups: 82 participants who met the criteria for IA and 114 participants who met less than 5 criteria. Among the participants with IA, the following main activities were specified: gaming $(n=30)$, use of SNSs $(n=30)$, and other applications, such as entertainment, downloading, online shopping or selling, pornography, searching information about current issues or news, and visiting dating sites $(n=22)$. Results of a non-response analysis showed that those who did not agree to be contacted or could not be reached for the follow-up were more likely to have a parent born outside of Germany $(p<.001)$ and were more likely to have less than 10 years of school education. Differences in gender, age, status, and CIUS scores could not be observed (Zadra et al., 2016).

\section{Measures}

The Compulsive Internet Use Scale (CIUS). The CIUS scale was used to identify participants with elevated Internet engagement. It consists of 14 Items, which are displayed in a 5-point Likert scale ranging from "never" to "very often." Salience, withdrawal, loss of control, conflict, and coping with unpleasant moods are main criteria of this assessment instrument. Psychometric properties were found to be good. The English version shows a Cronbach's $\alpha$ of .89-.90 (Meerkerk et al., 2009). A study determining the factorial structure of the German version of the CIUS revealed a Cronbach's $\alpha$ of $.89(n=2,506)$. In addition, a confirmatory factor analysis showed that the CIUS scale has a one-factorial structure with a sufficient model fit (Peukert et al., 2012).

IA according to DSM-5 criteria. To determine IA, the DSM-5 criteria for IGD were used within a fully structured instrument based on the structure and principles of the Composite International Diagnostic Interview (CIDI; Wittchen et al., 1995). The DSM-5 criteria were adapted to fit all potential problematic Internet-related activities by substituting the word "gaming" with "Internet activities." 


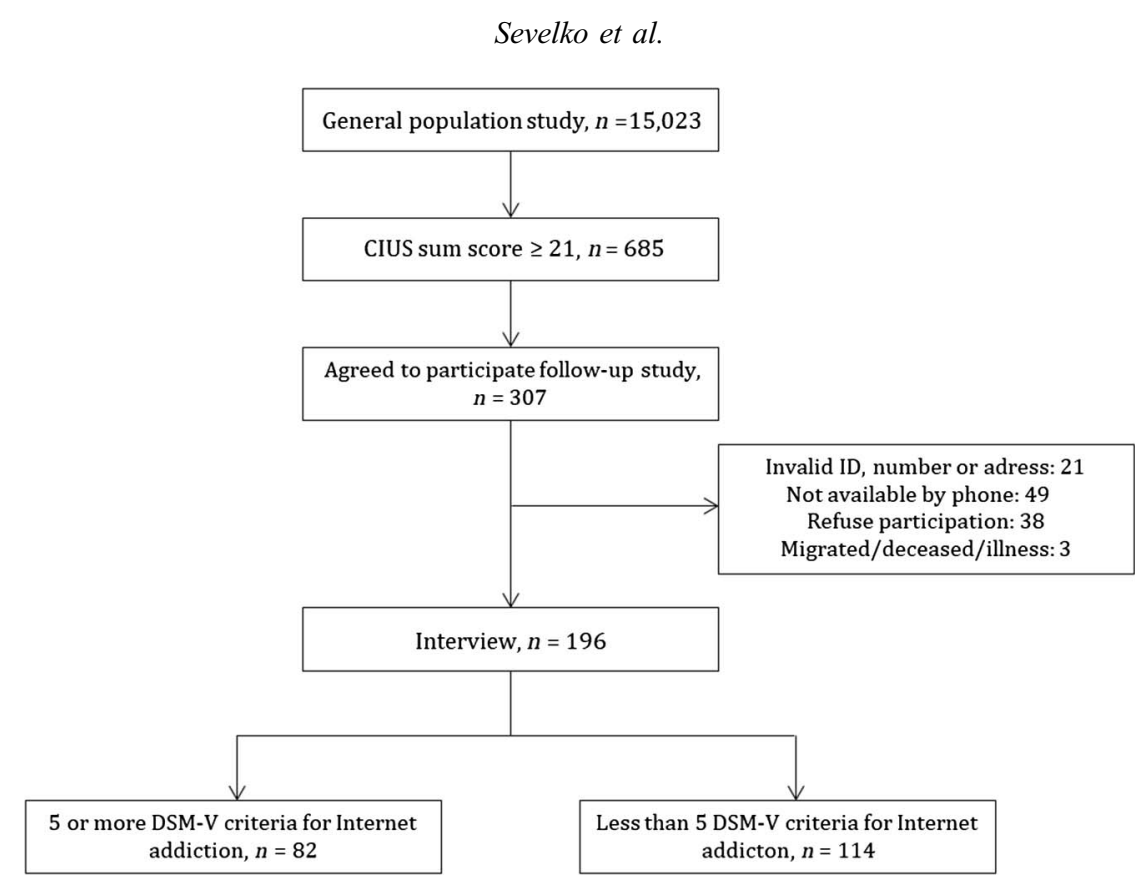

Figure 1. Recruitment flowchart

The nine criteria were assessed with 27 questions, where each criterion was covered by one to four questions. If five or more criteria were met, diagnosis of IA was fulfilled. The cut-off of 5 was confirmed in studies from Ko et al. (2014) and Rehbein, Kliem, Baier, Mößle, and Petry (2015). Unpublished data suggest excellent reliability for a lifetime diagnosis $(Y=.86)$ and likewise for a diagnosis within the past year (Yule's $Y=.84$ ). This was measured in a student's sample $(n=66)$ scoring 20 point or more on the CIUS. These participants were interviewed twice within an average period of 40 days. For the present analyses, lifetime diagnosis of IA was used.

Munich-Composite International Diagnostic Interview (M-CIDI). The diagnostic assessment of axis I disorders was carried out with the M-CIDI (Wittchen et al., 1995). This fully standardized diagnostic interview was developed for epidemiological surveys and research with the purpose to identify various symptoms and mental disorders. This instrument is capable of determining mental disorders in accordance with the ICD-10 Diagnostic Criteria for Research and has shown good retest reliability for most DSM-IV symptoms and disorders. Cohen's $\kappa$ coefficient is above 0.72 for most disorders, except bulimia and generalized anxiety disorder (Wittchen, Lachner, Wunderlich, \& Pfister, 1998). For this study, the following sections were included: tobacco dependence, anxiety disorders, mood disorders, alcohol dependence and abuse, substance dependence and abuse, and eating disorder.

Rosenberg's Self-esteem Scale (RSES). The RSES (Rosenberg, 1965) is a widely used measurement for evaluating global self-esteem. It consists of 10 items; half of them are positively phrased and the other half negatively. The Likert-type scale ranges from 0 to 3 with the following responses: strongly disagree, disagree, agree, and strongly agree. Internal consistency for the 10 items ranged between $\alpha=.84-.95$ with average of $\alpha=.90$ (Sinclair et al., 2010).

\section{Procedure}

This study uses data from the "Prevalence of Internet Use Disorder: Diagnostics and Risk profiles (PINTA-DIARI)" project. This study is based on a large, representative nationwide study in Germany called the PAGE study (Meyer et al., 2015). A part of the initial sample was interviewed face-to-face for a second time. These interviews were conducted either at the homes of the participants or, if desired, at another convenient location in their hometown. Interviews were carried out by trained interviewers with a background in clinical psychology. PAGE was funded by the German federal states; PINTA and PINTA-DIARI were funded by the German Federal Ministry of Health.

\section{Statistical analysis}

SPSS Statistics 22 (Chicago, IL, USA) was used for statistical analysis. Logistic regression models were used to investigate the relationship between IA and self-esteem. The comparison between the groups with and without IA was performed using $\chi^{2}$ test or Mann-Whitney $U$ Test. For the multivariate data analysis with IA as the dependent variable, a logistic regression analysis was used. Odds ratios (ORs) and 95\% confidence intervals (CIs) are shown. Selfesteem and comorbidities were analyzed in the same model to test if the factors were independent from each other.

\section{Ethics}

The study procedures were carried out in accordance with the Declaration of Helsinki. The PAGE and PINTA-DIARI study were approved by the ethics committees of the University of Lübeck, Lübeck, Germany and the University of Greifswald, Greifswald, Germany. All subjects were informed about the study and all provided informed consent for participation. Parental consent was sought for those younger than 18 years of age. 


\section{RESULTS}

\section{Descriptive data}

Among the total sample $(n=196), 82$ participants $(41.8 \%)$ could be identified as having IA. Descriptive characteristics of the sample are shown in Table 1.

There were no significant differences in age, gender, employment status, and migration background between groups. In the group with IA, 36.6\% played mainly online games, $36.6 \%$ used mainly SNSs and $26.8 \%$ reported other main online activities. The majority of participants with IA who stated online gaming as their main activity were male $(82.2 \%)$, whereas participants with IA reporting social networking as their main activity were mostly female $(80.6 \%)$.

\section{The influence of self-esteem on IA}

For the analysis of self-esteem in IA, two participants had to be excluded due to missing data in the RSES. Hence, the sample size used for this analysis was $n=194$. A binary logistic regression analysis of IA with self-esteem showed that for each one unit increase in self-esteem, the probability of having IA significantly decreased by $11 \%[\operatorname{Exp}(B)=$ $0.89 ; 95 \%$ CI $(0.83,0.96) ; p=.003]$.

\section{Comorbidities in $I A$}

Of the 82 participants with IA, 61 (74.4\%) had a cooccurring axis I disorder. Substance-use disorder and mood disorders were the most prevalent mental disorders in this group (Table 2).

Table 1. Descriptive data of the sample

\begin{tabular}{|c|c|c|c|c|}
\hline & Total & IA & Not IA & \\
\hline & $n=196(\%)$ & $n=82(\%)$ & $n=114(\%)$ & $p$ value \\
\hline Age $(M \pm S D)$ & $30.68 \pm 12.98$ & $29.04 \pm 11.81$ & $31.87 \pm 13.69$ & .24 n.s. \\
\hline \multicolumn{5}{|l|}{ Gender } \\
\hline Female & $98(50)$ & $40(51.2)$ & $58(50.9)$ & \multirow[t]{2}{*}{.77 n.s. } \\
\hline Male & $98(50)$ & $42(48.8)$ & $56(49.1)$ & \\
\hline \multicolumn{5}{|l|}{ Years of schooling } \\
\hline$<10$ th class & $18(9.2)$ & $5(6.1)$ & $13(11.4)$ & \multirow[t]{2}{*}{.21 n.s. } \\
\hline$\geq 10$ th class & $178(90.8)$ & 77 (93.9) & $101(88.6)$ & \\
\hline \multicolumn{5}{|l|}{ Migration $^{\mathrm{a}}$} \\
\hline Migration background & $47(24.4)$ & $21(25.9)$ & $26(23.2)$ & \multirow[t]{2}{*}{.66 n.s. } \\
\hline No migration background & $146(75.6)$ & $60(74.1)$ & $86(76.8)$ & \\
\hline \multicolumn{5}{|l|}{ Main activity online } \\
\hline Online games & $53(27)$ & $30(36.6)$ & $23(20.2)$ & \multirow[t]{3}{*}{$.01 * *$} \\
\hline Social networks & $70(35.7)$ & $30(36.6)$ & $40(35.1)$ & \\
\hline Other applications & $73(37.2)$ & $22(26.8)$ & $51(44.7)$ & \\
\hline
\end{tabular}

Note. $n$ : valid values (\%); IA: Internet addiction; $S D$ : standard deviation; n.s.: not significant.

${ }^{a} n=193$ due to missing values.

$* * p \leq .01$.

Table 2. Comorbidities in participant with and without IA

\begin{tabular}{|c|c|c|c|}
\hline & IA & No IA & \\
\hline Disorders & $n=82(\%)$ & $n=114(\%)$ & $p$ value \\
\hline Any assessed axis I mental disorders & $61(74.4)$ & $71(62.3)$ & .09 n.s. \\
\hline Any assessed axis I mental disorder excl. tobacco dependency & $59(72.0)$ & $60(52.6)$ & $.008^{* *}$ \\
\hline Any assessed axis I mental disorder excl. substance-use disorders & $47(57.3)$ & $46(40.4)$ & $.02 *$ \\
\hline Substance-use disorders & $44(53.7)$ & $49(43.0)$ & $.15 \mathrm{n} . \mathrm{s}$ \\
\hline Alcohol-use disorders & $28(34.1)$ & $25(21.9)$ & $.07 \mathrm{n} . \mathrm{s}$ \\
\hline Tobacco dependence & $26(31.7)$ & $39(34.2)$ & .76 n.s. \\
\hline Illegal drug-use disorders & $10(12.2)$ & $10(8.8)$ & .48 n.s. \\
\hline Substance-use disorders excluding tobacco dependence & $24(29.3)$ & $21(18.4)$ & $.04 *$ \\
\hline Mood disorders & $41(50.0)$ & $32(28.1)$ & $.003 * *$ \\
\hline Depressive disorders & $36(43.9)$ & $30(26.3)$ & $.01 *$ \\
\hline Anxiety disorders & $22(26.8)$ & $27(23.7)$ & $.62 \mathrm{n} . \mathrm{s}$. \\
\hline Social anxiety & $7(8.5)$ & $7(6.1)$ & .58 n.s. \\
\hline Eating disorders & $9(11.0)$ & $3(2.6)$ & $.03^{*}$ \\
\hline
\end{tabular}

Note. $n$ : valid values (\%); IA: Internet addiction; $S D$ : standard deviation; n.s.: not significant.

$* p \leq .05$. $* * p .01$. 
Comparison of axis I disorders between participants with and without IA

Participants with IA were more likely to have substance-use disorders (without tobacco dependence), mood disorders, and eating disorders compared to non-IA participants. There was a statistical tendency for alcohol-use disorders $(p=.06)$ and no differences for tobacco dependence, illegal drug use disorders, and anxiety disorders (Table 2).

\section{Influence of self-esteem and psychopathology/comorbidities}

Before conducting the main calculation, a pre-analysis was made. Each comorbid condition that showed significant differences between IA and Non-IA was tested in a logistic regression model including self-esteem. The purpose was to examine the specific impact of each mental disorder in relationship to self-esteem as a predictor of IA. The results can be seen in Table 3 .

To address the last hypothesis, substance-use disorders, mood disorders, and eating disorders were put into a logistic regression model along with self-esteem. Anxiety disorders have been ruled out due to their lack of significance. Substance-use disorders have been included without tobacco. An additional model included all comorbid disorders as an aggregate variable (any assessed axis I disorder). Table 4

Table 3. Logistic regression of IA with self-esteem and individual mental disorders

\begin{tabular}{lcl}
\hline Predicting constructs for IA & $\begin{array}{c}\text { Odds ratio } \\
{[95 \% \mathrm{CI}]}\end{array}$ & $\begin{array}{c}p \\
\text { value }\end{array}$ \\
\hline Self-esteem & $0.88[0.82-0.95]$ & $.002^{* *}$ \\
Substance-use disorder excluding & $1.43[1.05-1.98]$ & $.03^{*}$ \\
$\quad$ tobacco & & \\
Self-esteem & $0.91[0.84-0.98]$ & $.01^{* *}$ \\
Mood disorders & $1.48[1.09-2.01]$ & $.01^{* *}$ \\
Self-esteem & $0.89[0.83-0.96]$ & $.004^{* *}$ \\
Anxiety disorders & $1.01[0.71-1.42]$ & .96 n.s. \\
Self-esteem & $0.90[0.83-0.97]$ & $.008^{* *}$ \\
Eating disorder & $1.86[0.94-3.70]$ & .08 n.s. \\
\hline
\end{tabular}

Note. IA: Internet addiction; CI: confidence interval; n.s.: not significant.

${ }^{*} p \leq .05 .{ }^{* *} p \leq .01$

Table 4. Logistic regression of IA with self-esteem and psychiatric disorders in two separate models

\begin{tabular}{lcl}
\hline $\begin{array}{l}\text { Predicting constructs separate } \\
\text { models for IA }\end{array}$ & $\begin{array}{c}\text { Odds ratio } \\
{[95 \% \mathrm{CI}]}\end{array}$ & $\begin{array}{c}p \\
\text { value }\end{array}$ \\
\hline Model 1 & & \\
$\quad$ Self-esteem & $0.90[0.84-0.98]$ & $.02 *$ \\
$\quad \begin{array}{l}\text { Substance-use disorders } \\
\text { excluding tobacco }\end{array}$ & $1.37[0.98-1.89]$ & .06 n.s. \\
$\quad$ Mood disorders & $1.39[1.01-1.91]$ & $.04 *$ \\
$\quad$ Eating disorder & $1.66[0.82-3.37]$ & .16 n.s. \\
Model 2 & & \\
$\quad$ Self-esteem & $0.89[0.83-0.96]$ & $.004^{* *}$ \\
$\quad$ Any assessed axis I disorder & $1.29[0.94-1.78]$ & .12 n.s. \\
\hline
\end{tabular}

Note. IA: Internet addiction; CI: confidence interval; n.s.: not significant.

${ }^{*} p \leq .05 .{ }^{* *} p \leq .01$. depicts the outcome of this analysis, revealing that selfesteem emerged as a significant factor in both models.

\section{DISCUSSION}

The aim of this study was to evaluate the relation of selfesteem and psychopathology with IA in a sample of excessive Internet users. By applying the current DSM-5 criteria and recruiting participants based on a representative general population sample, some methodological issues of the past studies could be overcome. For the first hypothesis, the link between self-esteem and IA was assessed. The results indicated that people with low self-esteem are more prone toward developing IA or vice versa; individuals with IA have lower self-esteem. For each unit increase in self-esteem, the probability of IA decreases by $11 \%$. Considering that the RSES has a range from 0 to 30 , this can be regarded as a strong relationship. It is important to emphasize that the comparison was made between groups that both have elevated scores on excessive Internet use and only differ in fulfillment of the IA criteria based on the DSM-5 approach. Thus, the specific properties distinguishing IA from only frequent use are examined. For individuals with low self-esteem, certain Internet activities offer compensation for their perceived deficiencies (Aydm \& San, 2011). Another study found that high self-esteem can be a protecting factor, whereas low self-esteem is a risk factor (Beard et al., 2017). A multitude of studies established the link between IA and self-esteem (Andreassen et al., 2017; Beard et al., 2017; Kim \& Haridakis, 2009). In the light of the present outcome with the population-based sample, findings could be replicated.

As in other studies, our findings show that mood disorders and substance-use disorders are related to IA. The relationship between IA and depressive disorder has been reported throughout many papers (Akin \& Iskender, 2011; Andreassen et al., 2016; Yen, Ko, Yen, Wu, \& Yang, 2007). Excessive gaming has been found to have a negative effect on the well-being of gamers, which can contribute to developing depression. On the other side, online games can be used as a coping strategy for depressive symptoms, which would make these activities more addictive (Stetina, Kothgassner, Lehenbauer, \& Kryspin-Exner, 2011). This is similar to SNSs. Chou and Edge (2012) argued that social networking use could create or strengthen the belief that other people online have a better life. This belief could support depressive symptoms.

On an aggregate level, substance-use disorders gained significance only if tobacco dependence was excluded. Tobacco dependence appeared to be the only condition that is present more often in the group of non-addicted Internet users, despite not significantly. This suggests that tobacco dependence plays no relevant role in IA and thus was excluded in the analyses for the last hypothesis. Studies have shown that adolescents with dysfunctional Internet engagement tend to exhibit pathological substance use (Black, Belsare, \& Schlosser, 1999; Ko et al., 2006), which is in line with the present findings.

There were very few individuals with eating disorders in the sample. Yet, in the comparison between groups, eating disorder occurred significantly more often in the 
Internet-addicted group. One study looked at the negative impact of social media and television on the body image of females and how it affects eating disorder symptoms. However, they could not report any findings concerning that matter, except a correlation between social media use and low life satisfaction (Ferguson, Munoz, Garza, \& Galindo, 2014). Otherwise, there are barely any studies connecting these two disorders. Therefore, further studies on this matter to verify the present outcomes would be interesting.

In a brief overview, Griffiths, Kuss, and Pontes (2016) summarized that IGD is connected to symptoms of generalized anxiety disorder, panic disorder, and social phobia. However, in this study, the occurrence of anxiety disorders was not significantly different between those with and without IA. These results are not in accordance with what other studies found. For instance, in a recent study, Pearcy, McEvoy, and Roberts (2017) observed that individuals diagnosed with IGD were more likely to have a generalized anxiety disorder. Another study found a correlation between IA and social anxiety in university students (Weinstein et al., 2015) and in a meta-analysis anxiety was associated with IA (Ho et al., 2014). Shepherd and Edelmann (2005) suggested that people with social phobia would favor online interaction, where the stress of face-to-face interaction can be avoided. This could lessen the motivation to connect with people outside the Internet, since social support is easily available this way. Thus, these individuals would have a higher risk of becoming dependent on Internet activities. Our data could not support these findings. A possible explanation could be that this study compared two groups in which both are frequently using the Internet, rather than checking differences between Internet-addicted users to non- or light Internet users. The groups differed only in fulfilling or not fulfilling the DSM-5-based diagnosis, but both scored 21 and above on the CIUS scale. Hence, anxiety disorders may be related to frequent Internet use, but not to IA per se. In addition, a study by Ko, Yen, Chen, Chen, and Yen (2008) has questioned previous research on social anxiety and IA. They discovered that social anxiety was no longer correlated with IA when the model was controlled for attention-deficit hyperactivity disorder and depression. Considering the mixed outcomes in previous studies, further research is needed.

Overall, psychopathology is more frequent in the IA group. As can be seen in the results, the overall axis I mental disorders (excluding tobacco dependence) were significantly more common in IA. Individuals suffering from mental disorders might use certain Internet activities to cope or distract themselves from negative feelings related to their mental condition. On the other hand, increased engagement with Internet activities can cause negative consequences, which then can lead to the development of a comorbid disorder. Floros, Siomos, Stogiannidou, Giouzepas, and Garyfallos (2014) found that of the 51.85\% with a comorbid axis I disorder, $33.3 \%$ experienced IA after the onset of a previous mental disorder. In $14.81 \%$, it was unclear which disorder was experienced first. Since comorbidities affect treatment outcomes heavily (Borkovec, Abel, \& Newman, 1995), it is important to take them into account.
To examine the relationship of comorbidity and self-esteem, two regression models were calculated, one including each mental disorder, and one with comorbidity as an aggregate variable.

In all models, self-esteem remained stable suggesting that it is associated independently from the respective comorbid disorder with IA.

There are no previous studies directly comparing the influence of self-esteem and psychopathology on IA. Most scientific papers agree that both constructs are important risk-factors contributing to the development and maintenance of IA (Brand et al., 2016). In the I-PACE model by Brand et al. (2016), low self-esteem is regarded as a risk factor with respect to personality characteristics, such as impulsivity or low conscientiousness. Psychopathology is regarded as a different set of risk-factors. Although both set of risk factors are interrelated in the direction that, for example, self-esteem is lowered in individuals with depression, anxiety, or other mental disorders, our findings indicate that the risk of low self-esteem cannot be explained by comorbid conditions.

This sample does not solely focus on adolescents or gathers data in online survey nor is it limited to a clinical sample. By gathering data from a population-based sample, the study design and results go beyond previous research. In addition, this study specifically provides information on distinguishing variables between frequent Internet users and dysfunctional users.

In addition to the methodological advantages of this study, a number of limitations should be considered. While the initial sample was representative for the general population of Germany, the present one used the CIUS to select participants with extensive Internet use. Only a part of them could be reinterviewed. As mentioned above, a nonresponder analysis has revealed that participants with migration background and with less than 10 years of school education were more likely to decline participation. Therefore, certain groups of the population are systematically underrepresented. This study has examined IA as a general construct. However, IA has been often viewed in context of the application used. Further studies into this matter, distinguishing between the respective applications, could provide additional informational value. The assessment of mental disorders with the CIDI was performed using dichotomous variables, while self-esteem had a dimensional scale. However, a binary response does not offer much variance and thus limits the informational value of the statistical analysis. Finally, although the CIDI has good psychometric properties, criteria used in this study are based on the outdated DSM-IV. Due to the cross-sectional nature of the data, no causal conclusions can be drawn.

\section{CONCLUSIONS}

In this study, the relationship between low self-esteem and IA could be confirmed. Self-esteem has a significant impact on IA that cannot fully be explained by psychopathology. The addictive use of the Internet is also associated with mood disorder, substance-use disorder (excluding tobacco), and eating disorder, as well as psychopathology in general. 
This implies that certain individuals are more at risk for developing IA. Therefore, preventive measures targeting these people could prove beneficial. Moreover, these findings are also of importance for clinicians, since comorbidities are strongly related to treatment approaches and outcomes. The role of eating and anxiety disorders should be further investigated. Especially, the role of anxiety disorders in IA remains unclear. Although the majority of studies find a relationship between anxiety and IA, ours and some others do not. This might be related to sampling strategies. In a nutshell, low self-esteem and comorbidities are common in IA. This is why it would be a grave error to neglect them in prevention, treatment, or etiological models.

Funding sources: This work was supported by German Federal States and German Federal Ministry of Health.

Authors' contribution: KS: statistical analysis, interpretation of findings, and preparation of manuscript draft. GB: study concept and design. BB: data gathering. AB: study concept and design and data gathering. CM and UJ: study concept and design and obtained funding. H-JR: study concept and design, obtained funding, statistical analysis, and interpretation of findings. All authors had full access to all data in the study and take responsibility for the integrity of the data and the accuracy of the data analysis.

Conflict of interest: The authors declare no conflict of interest.

\section{REFERENCES}

Akin, A., \& Iskender, M. (2011). Internet addiction and depression, anxiety and stress. International Online Journal of Educational Sciences, 3(1), 138-148.

American Psychiatric Association. (2013). Diagnostic and statistical manual of mental disorders $\left(D S M-5^{\circledR}\right)$. Washington, DC: American Psychiatric Association.

Andreassen, C. S., Billieux, J., Griffiths, M. D., Kuss, D. J., Demetrovics, Z., Mazzoni, E., \& Pallesen, S. (2016). The relationship between addictive use of social media and video games and symptoms of psychiatric disorders: A large-scale cross-sectional study. Psychology of Addictive Behaviors, 30(2), 252-262. doi:10.1037/adb000016010.1037/ adb0000160

Andreassen, C. S., \& Pallesen, S. (2014). Social network site addiction - An overview. Current Pharmaceutical Design, 20(25), 4053-4061. doi:10.2174/13816128113199990616

Andreassen, C. S., Pallesen, S., \& Griffiths, M. D. (2017). The relationship between addictive use of social media, narcissism, and self-esteem: Findings from a large national survey. Addictive Behaviors, 64, 287-293. doi:10.1016/j.addbeh. 2016.03.006

Aydm, B., \& San, S. V. (2011). Internet addiction among adolescents: The role of self-esteem. Procedia - Social and Behavioral Sciences, 15, 3500-3505. doi:10.1016/j.sbspro. 2011.04.325
Beard, C. L., Haas, A. L., Wickham, R. E., \& Stavropoulos, V. (2017). Age of initiation and Internet gaming disorder: The role of self-esteem. Cyberpsychology, Behavior, and Social Networking, 20(6), 397-401. doi:10.1089/cyber.2017.0011

Beutel, M. E., Brähler, E., Glaesmer, H., Kuss, D. J., Wölfling, K., \& Müller, K. W. (2011). Regular and problematic leisure-time Internet use in the community: Results from a German population-based survey. Cyberpsychology, Behavior, and Social Networking, 14(5), 291-296. doi:10.1089/cyber.2010.0199

Black, D. W., Belsare, G., \& Schlosser, S. (1999). Clinical features, psychiatric comorbidity, and health-related quality of life in persons reporting compulsive computer use behavior. The Journal of Clinical Psychiatry, 60(12), 839-844. doi:10.4088/JCP.v60n1206

Borkovec, T., Abel, J. L., \& Newman, H. (1995). Effects of psychotherapy on comorbid conditions in generalized anxiety disorder. Journal of Consulting and Clinical Psychology, 63(3), 479-483. doi:10.1037/0022-006X.63.3.479

Brand, M., Young, K. S., Laier, C., Wölfling, K., \& Potenza, M. N. (2016). Integrating psychological and neurobiological considerations regarding the development and maintenance of specific Internet-use disorders: An Interaction of PersonAffect-Cognition-Execution (I-PACE) model. Neuroscience and Biobehavioral Reviews, 71, 252-266. doi:10.1016/j. neubiorev.2016.08.033

Chou, H.-T. G., \& Edge, N. (2012). "They are happier and having better lives than I am": The impact of using Facebook on perceptions of others' lives. Cyberpsychology, Behavior, and Social Networking, 15(2), 117-121. doi:10.1089/cyber. 2011.0324

Ferguson, C. J., Munoz, M. E., Garza, A., \& Galindo, M. (2014). Concurrent and prospective analyses of peer, television and social media influences on body dissatisfaction, eating disorder symptoms and life satisfaction in adolescent girls. Journal of Youth and Adolescence, 43(1), 1-14. doi:10.1007/s10964-0129898-9

Floros, G., Siomos, K., Stogiannidou, A., Giouzepas, I., \& Garyfallos, G. (2014). Comorbidity of psychiatric disorders with Internet addiction in a clinical sample: The effect of personality, defense style and psychopathology. Addictive Behaviors, 39(12), 1839-1845. doi:10.1016/j. addbeh.2014.07.031

Griffiths, M. D. (1995). Technological addictions. Clinical Psychology Forum, 76, 14-19.

Griffiths, M. D., Kuss, D. J., \& Demetrovics, Z. (2014). Social networking addiction: An overview of preliminary findings. In L. C. Feder (Ed.), Behavioral addictions (pp. 119-141). San Diego, CA: Academic Press.

Griffiths, M. D., Kuss, D. J., \& Pontes, H. M. (2016). A brief overview of Internet Gaming Disorder and its treatment. Australian Clinical Psychologist, 2(1), 20108.

Ho, R. C., Zhang, M. W. B., Tsang, T. Y., Toh, A. H., Pan, F., Lu, Y., Cheng, C., Yip, P. S., Lam, L. T., Lai, C. M., Watanabe, H., \& Mak, K.-K. (2014). The association between Internet addiction and psychiatric co-morbidity: A meta-analysis. BMC Psychiatry, 14(1), 183. doi:10.1186/ 1471-244X-14-183

Kardefelt-Winther, D. (2014). The moderating role of psychosocial well-being on the relationship between escapism and excessive online gaming. Computers in Human Behavior, 38, 68-74. doi:10.1016/j.chb.2014.05.020 
Kardefelt-Winther, D., Heeren, A., Schimmenti, A., Rooij, A., Maurage, P., Carras, M., Edman, J., Blaszczynski, A., Khazaal, Y., \& Billieux, J. (2017). How can we conceptualize behavioural addiction without pathologizing common behaviours? Addiction, 112(10), 1709-1715. doi:10.1111/add. 13763

Kim, J., \& Haridakis, P. M. (2009). The role of Internet user characteristics and motives in explaining three dimensions of Internet addiction. Journal of Computer-Mediated Communication, 14(4), 988-1015. doi:10.1111/j.1083-6101. 2009.01478.x

Ko, C. H., Yen, J.-Y., Chen, C.-C., Chen, S.-H., Wu, K., \& Yen, C.-F. (2006). Tridimensional personality of adolescents with Internet addiction and substance use experience. The Canadian Journal of Psychiatry, 51(14), 887-894. doi:10.1177/070674370605101404

Ko, C. H., Yen, J. Y., Chen, C. S., Chen, C. C., \& Yen, C. F. (2008). Psychiatric comorbidity of Internet addiction in college students: An interview study. CNS Spectrums, 13(2), 147-153. doi: $10.1017 / \mathrm{S} 1092852900016308$

Ko, C. H., Yen, J. Y., Chen, S. H., Wang, P. W., Chen, C. S., \& Yen, C. F. (2014). Evaluation of the diagnostic criteria of Internet gaming disorder in the DSM-5 among young adults in Taiwan. Journal of Psychiatric Research, 53, 103-110. doi:10.1016/j.jpsychires.2014.02.008

Kuss, D. J., Dunn, T. J., Wölfling, K., Müller, K. W., Hędzelek, M., \& Marcinkowski, J. (2017). Excessive Internet use and psychopathology: The role of coping. Clinical Neuropsychiatry: Journal of Treatment Evaluation, 14(1), 73-81.

Kuss, D. J., Griffiths, M. D., Karila, L., \& Billieux, J. (2014). Internet addiction: A systematic review of epidemiological research for the last decade. Current Pharmaceutical Design, 20(25), 4026-4052. doi:10.2174/1381612811319 9990617

Lampen-Imkamp, S., \& te Wildt, B. T. (2009). Phaenomenologie, Diagnostik und Therapie der Internet-und Computerspielabhaengigkeit [Phenomenology, diagnosis, and therapy of Internet addiction and computer game addiction]. In J. Hardt, U. Cramer-Duencher, \& M. Ochs (Eds.), Verloren in virtuellen Welten. Computerspielsucht im Spannungsfeld von Psychotherapie und Paedagogik (pp. 120-131). Goettingen: Vandenhoeck \& Ruprecht.

Meerkerk, G. J., Van Den Eijnden, R. J. J. M., Vermulst, A. A., \& Garretsen, H. F. (2009). The Compulsive Internet Use Scale (CIUS): Some psychometric properties. CyberPsychology \& Behavior, 12(1), 1-6. doi:10.1089/cpb.2008.0181

Meyer, C., Bischof, A., Westram, A., Jeske, C., de Brito, S., Glorius, S., Schön, D., Porz, S., Gürtler, D., Kastirke, N., Hayer, T., Jacobi, F., Lucht, M., Premper, V., Gilberg, R., Hess, D., Bischof, G., John, U., \& Rumpf, H. J. (2015). The "Pathological Gambling and Epidemiology" (PAGE) study program: Design and fieldwork. International Journal of Methods in Psychiatric Research, 24(1), 11-31. doi:10.1002/ mpr. 1458

Müller, K. W., Beutel, M. E., Egloff, B., \& Wölfling, K. (2014). Investigating risk factors for Internet gaming disorder: A comparison of patients with addictive gaming, pathological gamblers and healthy controls regarding the Big Five personality traits. European Addiction Research, 20(3), 129-136. doi: $10.1159 / 000355832$
Pearcy, B. T., McEvoy, P. M., \& Roberts, L. D. (2017). Internet gaming disorder explains unique variance in psychological distress and disability after controlling for comorbid depression, OCD, ADHD, and anxiety. Cyberpsychology, Behavior, and Social Networking, 20(2), 126-132. doi:10.1089/cyber. 2016.0304

Peukert, P., Steffen, S., ElKasmi, J., Barth, G. M., Meerkerk, G.-J., \& Batra, A. (2012). Faktorielle Struktur der deutschen version der Compulsive Internet Use Scale (CIUS) nach konfirmatorischer Faktorenanalyse [Factorial structure of the German version of Compulsive Internet Use Scale (CIUS) after confirmatory factor analysis]. Zeitschrift für Klinische Psychologie und Psychotherapie, 41(2), 101-108. doi:10.1026/ 1616-3443/a000137

Rehbein, F., Kliem, S., Baier, D., Mößle, T., \& Petry, N. M. (2015). Prevalence of Internet gaming disorder in German adolescents: Diagnostic contribution of the nine DSM- 5 criteria in a state-wide representative sample. Addiction, 110(5), 842-851. doi:10.1111/add.12849

Rosenberg, M. (1965). Rosenberg Self-Esteem Scale (RSE). Acceptance and commitment therapy. Measures Package, 61, 52. doi:10.1037/t01038-000

Rumpf, H.-J., Vermulst, A. A., Bischof, A., Kastirke, N., Gürtler, D., Bischof, G., Meerkerk, G. J., John, U., \& Meyer, C. (2014). Occurence of Internet addiction in a general population sample: A latent class analysis. European Addiction Research, 20(4), 159-166. doi:10.1159/000354321

Schmitz, N., Kugler, J., \& Rollnik, J. (2003). On the relation between neuroticism, self-esteem, and depression: Results from the National Comorbidity Survey. Comprehensive Psychiatry, 44(3), 169-176. doi:10.1016/S0010-440X(03) 00008-7

Shepherd, R.-M., \& Edelmann, R. J. (2005). Reasons for Internet use and social anxiety. Personality and Individual Differences, 39(5), 949-958. doi:10.1016/j.paid.2005.04.001

Shotton, M. A. (1991). The costs and benefits of 'computer addiction'. Behaviour \& Information Technology, 10(3), 219-230. doi:10.1080/01449299108924284

Sinclair, S. J., Blais, M. A., Gansler, D. A., Sandberg, E., Bistis, K., \& LoCicero, A. (2010). Psychometric properties of the Rosenberg Self-Esteem Scale: Overall and across demographic groups living within the United States. Evaluation \& the Health Professions, 33(1), 56-80. doi:10.1177/0163278 709356187

Stetina, B. U., Kothgassner, O. D., Lehenbauer, M., \& KryspinExner, I. (2011). Beyond the fascination of online-games: Probing addictive behavior and depression in the world of online-gaming. Computers in Human Behavior, 27(1), 473-479. doi:10.1016/j.chb.2010.09.015

Valkenburg, P. M., Peter, J., \& Schouten, A. P. (2006). Friend networking sites and their relationship to adolescents' well-being and social self-esteem. CyberPsychology \& Behavior, 9(5), 584-590. doi:10.1089/cpb.2006.9.584

Weinstein, A., Dorani, D., Elhadfi, R., Bukovza, Y., Yarmulnik, A., \& Dannon, P. (2015). Internet addiction is associated with social anxiety in young adults. Annals of Clinical Psychiatry, 27(1), 4-9.

Wittchen, H. U., Beloch, E., Garczynski, E., Holly, A., Lachner, G., Perkonigg, A., Pfutze, E. M., Schuster, P., Vodermaier, A., Vossen, A., Wunderlich, U., \& Zieglgänsberger, S. (1995). Münchener Composite International Diagnostic 
Interview (M-CIDI), Version 2.2. München, Germany: Max-Planck-Institut für Psychiatrie.

Wittchen, H. U., Lachner, G., Wunderlich, U., \& Pfister, H. (1998). Test-retest reliability of the computerized DSM-IV version of the Munich-Composite International Diagnostic Interview (M-CIDI). Social Psychiatry and Psychiatric Epidemiology, 33(11), 568-578. doi:10.1007/s001270050095

World Health Organization [WHO]. (2018). ICD-11 for mortality and morbidity statistics. Retrieved September 22, 2018, from https://icd.who.int/browse11/1-m/en\#/http://id.who.int/icd/entity/ 1448597234

Yen, J. Y., Ko, C. H., Yen, C. F., Wu, H. Y., \& Yang, M. J. (2007). The comorbid psychiatric symptoms of Internet addiction: Attention deficit and hyperactivity disorder (ADHD), depression, social phobia, and hostility. Journal of Adolescent Health, 41(1), 93-98. doi:10.1016/j. jadohealth.2007.02.002

Young, K. S. (1996). Psychology of computer use: XL. Addictive use of the Internet: A case that breaks the stereotype. Psychological Reports, 79(3), 899-S902. doi:10.2466/pr0. 1996.79.3.899

Young, K. S. (1999). Internet addiction: Symptoms, evaluation and treatment. In L. VandeCreek \& T. L. Jackson (Eds.), Innovations in clinical practice: A source book (Vol. 17, pp. 19-31). Sarasota, FL: Professional Resource Press.

Zadra, S., Bischof, G., Besser, B., Bischof, A., Meyer, C., John, U., \& Rumpf, H. J. (2016). The association between Internet addiction and personality disorders in a general populationbased sample. Journal of Behavioral Addictions, 5(4), 691-699. doi:10.1556/2006.5.2016.086 